\title{
Effectiveness and cost of quick diagnostic tests to determine tetanus immunity in patients with a wound in french emergency departments
}

\author{
Dieynaba S N'Diaye ${ }^{1,2,3^{*}}$, Michaël Schwarzinger ${ }^{1,2}$, Dorothée Obach ${ }^{1,2}$, Julien Poissy ${ }^{4}$, Sophie Matheron ${ }^{5}$, \\ Enrique Casalino ${ }^{6}$ and Yazdan Yazdanpanah ${ }^{1,2,5}$
}

\begin{abstract}
Background: Tétanos Quick Stick ${ }^{\oplus}$ (TQS) is a test for tetanus immunity screening for wounded patients in emergency departments (EDs), but represents additional costs compared with a medical interview on vaccination history. The study objective was to assess the effectiveness and cost of the TQS in French EDs.

Methods: We performed a model-based analysis that simulates screening of tetanus immunity and risk of tetanus based on prophylaxis administration. Strategies compared were: i) diagnosis of tetanus immunity by "TQS"; ii) "Medical Interview" (current practice). The study population was 1,658,000 French adults seeking ED care for a wound in 2012. Model parameters were estimated based on French national surveillance data, and published literature. Outcome measures were number of tetanus cases, life years gained and costs (2012 €) from a societal perspective.

Results: Use of TQS had negligible impact on health outcomes ( 0.02 tetanus cases/year in France vs. 0.41 for "Medical Interview"), but resulted in a decrease in annual costs of $€ 2,203,000(-42 \%)$. Base case and sub-group analysis showed that with the same effectiveness, the average cost per patient was: $€ 13$ with "Medical Interview" vs. €11.7 with TQS for the overall cohort; €28.9 with "Medical Interview" vs. €21 with "TQS" for tetanus-prone wounds; $€ 15$ with "Medical Interview" vs. $€ 14.1$ with "TQS" for patients aged $\geq 65$ years; and $€ 6.2$ with "Medical Interview" vs. €7.8 with "TQS" for non-tetanus-prone wounds.

Conclusions: Use of TQS is as effective and less costly than "Medical Interview" when applied in ED to wounded patients with tetanus-prone wounds or aged $\geq 65$ years. However, it is more expensive in patients with non-tetanus-prone wounds.
\end{abstract}

Keywords: Tetanus immunity, Diagnostic tests, Cost-effectiveness, Emergency department

\section{Background}

In high-income countries, thanks to systematic immunization campaigns and prophylaxis strategies, tetanus is a rare disease. In France, the annual incidence rate of tetanus for the period 2000-2012 is estimated to be 0.27 cases per million inhabitants [1].

Alongside universal vaccination, unscheduled tetanus prophylaxis is administered to patients with a wound depending on its severity and the patient's vaccination status

\footnotetext{
* Correspondence: ndiayedieynaba@hotmail.fr

'INSERM, IAME, UMR 1137, F-75018 Paris, France

2Université Paris Diderot, IAME, UMR 1137, Sorbonne Paris Cité, F-75018 Paris, France

Full list of author information is available at the end of the article
}

(Table 1) [2,3]. Currently, in emergency departments (EDs), healthcare workers assess tetanus immunization status by asking for the patient's vaccination card or through a medical interview retracing the patient's vaccination history. However, patients rarely bring their vaccination cards, and multiple studies have shown that medical interviews lack accuracy [4-8]. For example, Colombet et al. reported that the sensitivity and specificity of this practice was $62 \%$ and $79 \%$, respectively [5].

Immunization status, as defined by serum tetanus antitoxin level, can now be more accurately determined through rapid testing using immunochromatographic methods. Colombet et al. recently showed that one of these tests, the Tétanos Quick Stick ${ }^{\bullet}$ TQS) (TQS; Ingen, 
Table 1 Guidelines for tetanus prophylaxis for wound management in French EDs

\begin{tabular}{|c|c|c|c|}
\hline \multirow[t]{3}{*}{ Type of wound } & \multicolumn{3}{|l|}{ Vaccination history } \\
\hline & \multicolumn{2}{|c|}{ Complete primary vaccination } & \multirow[t]{2}{*}{ No or unknown complete primary vaccination } \\
\hline & Booster $^{a}$ updated $^{b}$ & Booster not updated & \\
\hline Non-tetanus-prone wound & Nothing & Booster & Booster (proposal to update the primary vaccination) ${ }^{d}$ \\
\hline Tetanus-prone wound $^{c}$ & Nothing & Booster + TIG & Booster + TIG (proposal to update the primary vaccination) \\
\hline
\end{tabular}

ED: Emergency department; TIG: Human tetanus immunoglobulins;

${ }^{a}$ Tetanus-toxoid vaccine.

${ }^{\mathrm{b}}$ According to the French vaccination schedule; i.e. having received a tetanus-toxoid injection during the last 20 years for those $<65$ years of ageand during the last 10 years of those aged $\geq 65$ years.

'Such as (but not limited to) wounds contaminated with dirt, feces, soil, and saliva; puncture wounds; avulsions; and wounds resulting from missiles, crushing, burns, and frostbite.

dPrimary vaccination update: administration of two other boosters at a one-month interval, usually by a general practitioner.

France), was associated with a higher sensitivity and specificity than medical interview for immunization status determination [5]. However, such tests are associated with higher costs than the medical interview. The estimated unit cost of a test is $€ 4.7$ [9].

The objective of this study was, in the current context of implemented guidelines, to assess using a model-based analysis, in French patients presenting to the ED with wounds, the effectiveness, costs and cost-effectiveness of rapid tests and in particular TQS for tetanus immunization status determination vs. current practice based on the medical interview.

\section{Methods}

\section{Analytic overview}

We developed a decision-tree model that simulates the trajectory of a cohort of adult patients seeking care in EDs for a wound during the year 2012 in France. Each patient's trajectory incorporates wound type, tetanus immunization status diagnosis, administration of unscheduled tetanus prophylaxis according to immunization status, and the risk for tetanus and related survival with or without sequelae (Figure 1). Several parameters used in the model (immunization status, unscheduled vaccination guidelines, tetanus incidence) vary with age; we therefore stratified our adult study population into two age groups: $18-64$ years old and $\geq 65$ years. Since tetanus incidence and prophylaxis guidelines differ according to the type of wound, we also stratified the study population into patients with and without tetanus-prone wounds. The model was developed and analyzed using TreeAge Pro 2012 (TreeAge Software, Inc., Williamstown, MA).

\section{Strategies}

Two strategies to diagnose the tetanus immunization status were compared and applied each on the entire hypothetical cohort of patients considered in the analysis.

\section{(i) "Medical Interview" strategy (current practice)}

The "Medical Interview" is illustrated in Figure 1. Patients were first asked whether they had their vaccination card.
If they did, this card showed whether their last booster was up to date or not. If they did not, they are asked about their tetanus vaccination history in a medical interview. If they reported "No or unknown complete primary vaccination", based on French guidelines, they were given a booster and a human tetanus immunoglobulin (TIG) injection in the case of tetanus-prone wounds, and only a booster in the case of no tetanus-prone wounds. If the patients asserted having received a "Complete primary vaccination", they were asked if their boosters were up to date. Those replying yes received no prophylaxis; those replying no received a booster and a TIG injection in the case of tetanus-prone wounds and only a booster in the case of no tetanus-prone wounds.

\section{(ii) "TQS" strategy}

The "TQS" strategy is illustrated in Figure 1. As in the "Medical Interview" strategy, patients were first asked about their vaccination card. Patients without a vaccination card were systematically screened with a TQS. A positive test classified the patient as immune (i.e. with serum anti-tetanus antibody above $0.1 \mathrm{IU} / \mathrm{mL}$ of blood) [2]. Immune patients received no prophylaxis. A negative test classified the patient as non-immune (i.e. serum antitetanus antibody under the protective threshold). Nonimmune patients received unscheduled tetanus prophylaxis like patients in the "Medical Interview" strategy.

\section{Outcomes}

Based on this model, we estimated for each strategy the proportion of patients correctly and incorrectly diagnosed, the number of tetanus cases per year, and the cohort's life expectancy. We also assessed overall costs in order to calculate the incremental cost-effectiveness ratio (ICER) of the "TQS" strategy compared with current practice [10].

Since wound type determines ED care and has an impact on tetanus risk, we conducted a sub-analysis on tetanusprone and non-tetanus-prone wounds. Because patients aged $\geq 65$ years are less immune against tetanus, we also conducted a specific analysis in this population [11]. 

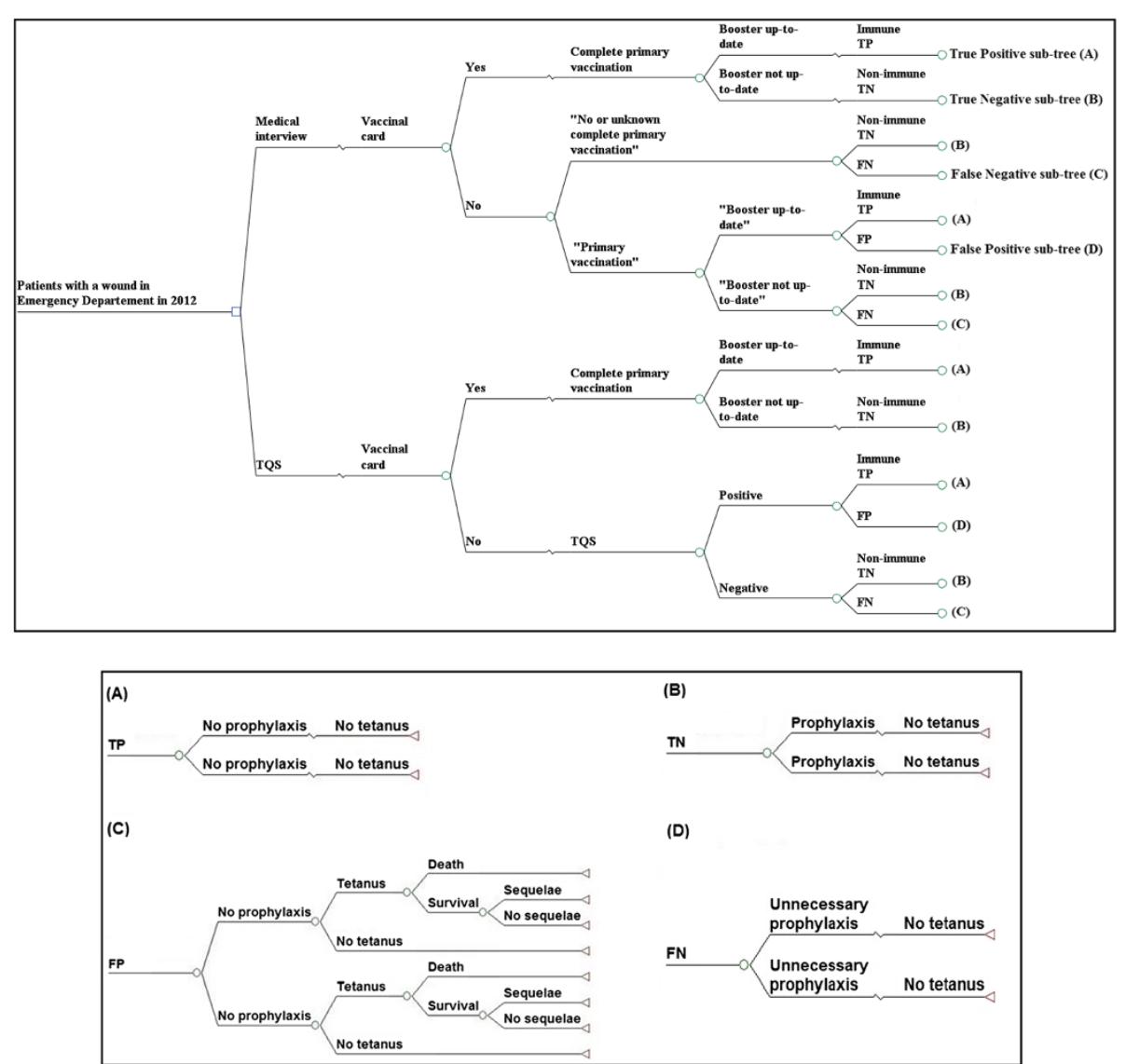

Figure 1 Decision-tree model: strategies compared and sub-trees. TQS: Tétanos Quick Stick; TP: True Positive; FP: False Negative; TN: True Negative; FN: False Negative (A) True Positive sub-tree; (B) True Negative sub-tree; (C) False Positive sub-tree; (D) False Negative sub-tree;

*For non-tetanus-prone wound; \# For tetanus-prone wound.

\section{Key assumptions}

Key simplifying assumptions in this model included the following:

1. If patients came to the ED with a vaccination card, the health care professional considered the card as written evidence of the patient's true immunization status.

2. We considered that patients who were not immune and who received appropriate tetanus prophylaxis would not develop tetanus.

\section{Data and sources}

Model input variable parameters were mainly estimated using national observational data and, when not available, through an extensive review of the international literature (Table 2).

Our study population was an annual cohort of wounded adults seeking care in an ED. These correspond to $13 \%$ of the 12.7 million adults annually seeking care in French EDs, $16.6 \%$ of whom were aged $\geq 65$ years, and $70.3 \%$ were male $[5,8,12,13]$. Children were not considered in this analysis because data on TQS and medical interview performance are lacking in this population. Based on Colombet et al. data, $31 \%$ of the patients had a tetanus-prone-wound [5].

The true immunization rate of patients aged 18-64 years was estimated to be $94.6 \%$ based on ELISA test results in the Colombet et al. study (see Additional file 1: Technichal Appendix) [5]. Seroprevalence in patients aged $\geq 65$ years was estimated as $76.6 \%$ using data from a study of vaccination coverage in this population by the Institut de Veille Sanitaire, which is the French Institute for Public Health Surveillance.

The probability of having a vaccination card when coming to the ED was estimated as $12 \%$ [5]. The performances of the two screening strategies in defining the immunization status of patients were estimated using the findings of Colombet et al. [5]. The sensitivity and specificity of TQS testing of blood samples in ED conditions were estimated to be $69 \%$ and $98 \%$, respectively [5]. Based on the same data, medical interview sensitivity and specificity were estimated as $62 \%$ and $79 \%$, respectively.

Tetanus incidence was estimated based on age, the type of wound, and the administration or not of 
Table 2 Model parameters base case values and ranges used in the sensitivity analyses

\begin{tabular}{|c|c|c|c|c|}
\hline Parameter & Base case value & Min & Max & Source \\
\hline $\begin{array}{l}\text { Annual number of patients } \geq 18 \text { years } \\
\text { coming to French EDs }\end{array}$ & $12,757,000$ & $12,223,000$ & $13,243,000$ & [12] \\
\hline $\begin{array}{l}\text { Cohort size (wounded patients } \geq 18 \text { years } \\
\text { coming to the French EDs) }\end{array}$ & $1,658,000$ & $1,589,000$ & $1,722,000$ & $\begin{array}{l}\text { Calculus based } \\
\text { on [13] and [12] }\end{array}$ \\
\hline Pr wound | ED consultation & $13.0 \%$ & $10.0 \%$ & $15.0 \%$ & [13] \\
\hline Pr tetanus-prone wound| wound & $31.0 \%$ & $18.1 \%$ & $77.3 \%$ & {$[5,6,14-17]$} \\
\hline Pr highly tetanus-prone wound | wound & $4.9 \%$ & & & [6] \\
\hline Pr patients $\geq 65$ years in the cohort & $16.6 \%$ & $10.0 \%$ & $20.0 \%$ & {$[8,12]$} \\
\hline Pr men in the cohort & $70.3 \%$ & $45.7 \%$ & $75.0 \%$ & {$[5,6,8,15,16]$} \\
\hline Life expectancy & $\begin{array}{l}\text { (Pr men in the cohort } \times \text { Average men's life expectancy } \\
\text { of the age group) }+((1-\operatorname{Pr} \text { men in the cohort) } \times \text { Average } \\
\text { women's life expectancy of the age group) }\end{array}$ & & & \\
\hline 18 to 64 years & 40.9 & 38.9 & 44.7 & [18] \\
\hline$\geq 65$ years & 9.1 & 8.4 & 10.4 & \\
\hline Pr vaccination card & $11.9 \%$ & $0.0 \%$ & $19.6 \%$ & {$[5,14,16]$} \\
\hline Medical interview sensitivity & $62.0 \%$ & $38.0 \%$ & $65.0 \%$ & [4-8] \\
\hline Medical interview specificity & $79.0 \%$ & $66.0 \%$ & $96.0 \%$ & [4-8] \\
\hline TQS sensitivity & $69.0 \%$ & $55.0 \%$ & $96.0 \%$ & {$[4-8,19,20]$} \\
\hline TQS specificity & $98.0 \%$ & $87.2 \%$ & $100.0 \%$ & {$[4-8,19,20]$} \\
\hline \multicolumn{5}{|l|}{ Seroprevalence ( $\geq 0.1 \mathrm{IU} / \mathrm{mL})$} \\
\hline 18 to 64 years & $94.6 \%$ & $84.0 \%$ & $96.6 \%$ & [5] \\
\hline$\geq 65$ years & $76.6 \%$ & $72.2 \%$ & $83.3 \%$ & [21] \\
\hline \multicolumn{5}{|l|}{ Pr of being up-to-date with booster shots } \\
\hline $\begin{array}{l}18 \text { and } 64 \text { years (last booster less than } \\
20 \text { years ago) }\end{array}$ & $71.2 \%$ & $70.0 \%$ & $81.0 \%$ & [22] \\
\hline $\begin{array}{l}\geq 65 \text { years (last booster less than } 10 \text { years } \\
\text { ago) }\end{array}$ & $44.0 \%$ & $44.0 \%$ & $77.0 \%$ & [11] \\
\hline \multirow[t]{2}{*}{ Pr of booster being assessed as up-to-date } & $\begin{array}{l}\text { (Medical interview sensitivity } \times \operatorname{Pr} \text { up-to-date } \\
\text { with boosters) + ((1-Medical interview specificity) }\end{array}$ & & & \\
\hline & $\times(1-\operatorname{Pr}$ up-to-date with boosters)) & & & \\
\hline 18 to 64 years & $50.2 \%$ & & & \\
\hline$\geq 65$ years & $39.0 \%$ & & & \\
\hline Pr positive TQS & $\begin{array}{l}\text { (TQS sensitivity } \times \text { Seroprevalence })+ \\
((1-\text { TQS specificity }) \times(1-\text { Seroprevalence }))\end{array}$ & & & \\
\hline 18 and 64 years & $65.7 \%$ & & & \\
\hline$\geq 65$ years & $53.3 \%$ & & & \\
\hline $\begin{array}{l}\text { Pr of patient reporting having } \\
\text { a complete primary vaccination }\end{array}$ & $69.9 \%$ & $71.5 \%$ & $50.4 \%$ & {$[5,15]$} \\
\hline Medical interview PPV & $\begin{array}{l}\text { Pr up-to-date with boosters } \times \text { Medical interview } \\
\text { sensitivity/((Pr up-to-date with boosters×Medical } \\
\text { interview sensitivity) }+((1-\operatorname{Pr} \text { up-to-date with } \\
\text { boosters }) \times(1-\text { Medical interview specificity) }))\end{array}$ & & & \\
\hline 18 to 64 years & $88.0 \%$ & & & \\
\hline$\geq 65$ years & $69.9 \%$ & & & \\
\hline Medical interview NPV & $\begin{array}{l}\text { (1-Pr up-to-date with boosters) } \times \text { Medical interview } \\
\text { specificity/(((1-Pr up-to-date with boosters) }\end{array}$ & & & \\
\hline
\end{tabular}


Table 2 Model parameters base case values and ranges used in the sensitivity analyses (Continued)

\begin{tabular}{|c|c|c|c|c|}
\hline & $\begin{array}{l}\times \text { Medical interview specificity })+(\operatorname{Pr} \text { up-to-date } \\
\text { with boosters } \times(1-\text { Medical interview sensitivity })))\end{array}$ & & & \\
\hline 18 to 64 years & $45.7 \%$ & & & \\
\hline$\geq 65$ years & $72.6 \%$ & & & \\
\hline TQS PPV & $\begin{array}{l}\text { SeroprevalenceXTQS sensitivity/((SeroprevalencexTQS } \\
\text { sensitivity) }+((1 \text {-Seroprevalence) } \times(1-T Q S \text { specificity) }))\end{array}$ & & & \\
\hline 18 to 64 years & $99.8 \%$ & & & \\
\hline$\geq 65$ years & $99.1 \%$ & & & \\
\hline TQS NPV & $\begin{array}{l}\text { (1-Seroprevalence) } \times \text { TQS specificity/(((1-Seroprevalence) } \times \text { TQS } \\
\text { specificity ) + (Seroprevalencex(1-TQS sensitivity))) }\end{array}$ & & & \\
\hline 18 to 64 years & $15.3 \%$ & & & \\
\hline$\geq 65$ years & $49.1 \%$ & & & \\
\hline TIG relative risk on tetanus occurrence & 0 & & & $\begin{array}{l}\text { Institut de veille } \\
\text { sanitaire expert } \\
\text { assumption }\end{array}$ \\
\hline $\begin{array}{l}\text { Tetanus vaccine relative risk on tetanus } \\
\text { occurrence }\end{array}$ & 1 & & & $\begin{array}{l}\text { Institut de veille } \\
\text { sanitaire expert } \\
\text { assumption }\end{array}$ \\
\hline Pr hospitalization | tetanus case & $100 \%$ & & & {$[23-26]$} \\
\hline \multicolumn{5}{|l|}{ Pr death | tetanus case } \\
\hline$<70$ years & $10.0 \%$ & $0 \%$ & $100.0 \%$ & {$[23-26]$} \\
\hline$\geq 70$ years & $27.2 \%$ & $0 \%$ & $42.0 \%$ & {$[23-26]$} \\
\hline Pr sequelae| surviving tetanus case & $31.6 \%$ & $18.8 \%$ & $50.0 \%$ & {$[23-26]$} \\
\hline c TQS (€ 2012) & $€ 4.7$ & $€ 4$ & $€ 5$ & {$[9,17]$} \\
\hline $\begin{array}{l}\text { C tetanus vaccine (Revaxis }{ }^{\oplus:} 0.5 \mathrm{~mL} \text { syringe) } \\
(€ 2012)\end{array}$ & $€ 10.0$ & $€ 3$ & $€ 15$ & {$[27]$} \\
\hline $\begin{array}{l}\text { c human TIG (Gammatetanos }{ }^{\oplus:} 250 \text { IU/2 mL } \\
\text { syringe) (€ 2012) }\end{array}$ & $€ 34,9$ & $€ 30$ & $€ 40$ & {$[27]$} \\
\hline c hospitalization tetanus case ( $€$ 2012) & $€ 209,000$ & $€ 150,000$ & $€ 250,000$ & {$[28]$} \\
\hline c sequelae of a tetanus case ( $€$ 2012) & $€ 5,663$ & $€ 5,000$ & $€ 6,000$ & [28] \\
\hline
\end{tabular}

Pr: probability; c: cost; | : among (in case of a conditional probabilities); ED: Emergency Department; TQS: Tétanos Quick Stick; TIG: Tetanus immunoglobulins; PPV: Positive predictive value; NPV: Negative predictive value; GP: General practitioner.

unscheduled tetanus prophylaxis. Tetanus incidence rates were calculated by age group and type of wound based on national observational data between 2000 and 2011 (see Additional file 1: Technical Appendix).

Specific tetanus incidence rates obtained were: for patients between $18-64$ years, 0.3 and 1.6 cases per million for non-tetanus-prone and tetanus-prone wounds respectively; and 8.8 and 41 cases per million for patients aged $\geq 65$ years (see Additional file 1: Technical appendix). In patients in whom tetanus occurred, we considered that the probability of being hospitalized was 1 . Mortality and the probability of long-term sequelae were estimated using data on the surveillance of tetanus from the French Institut de Veille Sanitaire [23-26].

\section{Costs}

The estimated cost of the TQS was $€ 4.7$ according to Lesimple et al. [9]. No TQS administration cost was considered, assuming that costs associated with the working time spent performing the test would be roughly equal to the time needed to conduct the medical interview. Treatment costs included tetravalent booster vaccine (Revaxis ${ }^{\circ}$, Sanofi Pasteur MSD: €10) and TIG (Gammatetanos, Laboratoire LFB Biomédicaments: €34.9) and were obtained from the Vidal (French equivalent of the Physicians' Desk Reference), an online database of information on healthcare products [27]. The cost of a tetanus case was estimated using national hospitalization statistics $(=€ 209,000)$ [28]. Costs related to tetanus sequelae were assessed by taking into account stays in the follow-up care and rehabilitation departments also using national hospitalization statistics and were estimated as $€ 5,390$ [28].

Outpatient costs related to tetanus cases were not included since in this analysis in this analysis since they were considered to be negligible when compared to hospitalization costs. In cost calculations, we adopted a societal perspective. We only included direct and differential medical costs between the strategies compared 
which were all supported by the French Health Insurance (in 2012 euros). The tetanus incidence is very low in France and the study perspective was fixed at one year [1]. Consequently, productivity cost were considered as negligible and not included. Since the study does not include human material or human data, because only published data from a literature review were used, the approval of an ethics committee was not needed.

\section{Sensitivity analysis}

In addition to a sub-analysis based on the nature of the wound (tetanus-prone or not) and the patient's age, oneway sensitivity analyses were performed for all probabilities and costs, to evaluate the robustness of our results and to explore the impact that parameter uncertainties. In those analyses, we used estimates for input variables found in the medical literature but not used in the base case analysis. When input variables were only from one study, a plausible range of values was built based on assumptions. For the parameters identified in the one-way sensitivity analysis as having a high impact on results, a threshold analysis was performed to determine at which values outside plausible ranges the choice of optimal strategy could be changed. We also considered and explored several scenarios in our sensitivity analysis. We considered cases where a monovalent vaccine or equine immunoglobulins were administered (see Additional file 1: Technical Appendix).

\section{Results}

Under current practice, our model predicted approximately one tetanus case per year among those who sought medical care in the ED for a wound. This correlated well with the observed number of tetanus cases per year in France caused by wound infection and that would have led to an ED consultation [23-26].

\section{Base-case analysis}

In the present context, for 1,658,000 patients presenting at the ED with wounds, the use of the "TQS" strategy resulted in 0.02 tetanus cases per year compared with 0.41 cases per year for "Medical Interview" (Table 3). The number of tetanus cases with each strategy was thus low and comparable. We will therefore only focus on costs and consider that the current analysis is a costminimization rather than a cost-effectiveness analysis.

The overall "TQS" strategy was less costly than "Medical Interview": $€ 19,361,000$ compared with $€ 21,564,000$. Increased costs incurred by TQS use $(€ 6,866,000)$ were offset by reduction of unnecessary prophylaxis $(€ 8,988,000)$ : $42 \%$ decreases in booster shots and TIG doses. The average cost per patient was: $€ 13$ with "Medical Interview" vs. $€ 11.7$ with "TQS" for the overall cohort.

\section{Sub-analysis results}

The two sub-groups where the TQS use generated the greatest savings were the tetanus-prone wounds $(€ 3,939,000)$ and the $18-64$ years old patients $(€ 1,956,000)$.

Table 3 Effectiveness and cost of tetanus immunity diagnostic strategies in wounded patients in French ED ${ }^{a, b}$

\begin{tabular}{|c|c|c|c|c|c|c|c|c|}
\hline Cohort & Strategies & $\begin{array}{l}\text { Tetanus } \\
\text { case }\end{array}$ & $\begin{array}{l}\text { Effectiveness } \\
\text { (LY) }\end{array}$ & $\begin{array}{l}\text { Vaccine } \\
\text { dose }\end{array}$ & $\begin{array}{l}\text { TIG } \\
\text { dose }\end{array}$ & $\begin{array}{l}\text { TQS } \\
\text { cost }\end{array}$ & $\begin{array}{l}\text { Prophylaxis } \\
\text { cost }\end{array}$ & $\begin{array}{l}\text { Total } \\
\text { cost }\end{array}$ \\
\hline All wounded patients & Medical Interview & 0.41 & $58,658,086.40$ & $1,033,000$ & 320,000 & - & $€ 21,478,000$ & $€ 21,564,000$ \\
\hline \multirow[t]{2}{*}{$N=1,658,000$} & TQS & 0.02 & $58,658,087.40$ & 601,000 & 186,000 & $€ 6,866,000$ & $€ 12,490,000$ & $€ 19,361,000$ \\
\hline & $\Delta^{C}$ & -0.39 & 1 & $-432,000$ & $-134,000$ & $€ 6,866,000$ & $€ 8,988,000$ & $\in 2,203,000$ \\
\hline Patients with a & Medical Interview & 0.13 & $40,494,923.00$ & 713,000 & - & - & $€ 7,118,000$ & $€ 7,145,000$ \\
\hline Non-tetanus-prone wound & TQS & 0.01 & $40,494,923.30$ & 415,000 & - & $€ 4,740,000$ & $€ 4,139,000$ & $€ 8,881,000$ \\
\hline$N=1,145,000$ & $\Delta$ & -0.13 & 0.3 & $-298,000$ & - & $€ 4,740,000$ & $\in 2,979,000$ & $€ 1,736,000$ \\
\hline Patients with a & Medical Interview & 0.28 & $18,163,163.40$ & 320,000 & 320,000 & - & $€ 14,360,000$ & $€ 14,419,000$ \\
\hline Tetanus-prone-wound & TQS & 0.02 & $18,163,164.10$ & 186,000 & 186,000 & $€ 2,126,000$ & $€ 8,351,000$ & $€ 10,480,000$ \\
\hline$N=513,000$ & $\Delta$ & -0.26 & 0.7 & $-134,000$ & $-134,000$ & $€ 2,126,000$ & $€ 6,009,000$ & $€ 3939,000$ \\
\hline Patients $18-64$ years & Medical Interview & 0.04 & $56,180,160.90$ & 838,000 & 260,000 & & $€ 17,048,000$ & $€ 17,438,000$ \\
\hline \multirow[t]{2}{*}{$N=1,383,000$} & TQS & 0 & $56,180,161.00$ & 469,000 & 145,000 & $€ 5,726,000$ & $€ 9,755,000$ & $€ 15,482,000$ \\
\hline & $\Delta$ & -0.04 & 0.10 & $-369,000$ & $-115,000$ & $€ 5,726,000$ & $\in 7,293,000$ & $\in 1,956,000$ \\
\hline Patients of 65 & Medical Interview & 0.37 & $2,477,925.50$ & 195,000 & 60,000 & - & $€ 4,430,000$ & $€ 4,126,000$ \\
\hline Years and over & TQS & 0.02 & $2,477,926.40$ & 132,000 & 41,000 & $€ 1,140,000$ & $€ 2,735,000$ & $€ 3,879,000$ \\
\hline$N=275,000$ & $\Delta$ & -0.35 & 0.9 & $-63,000$ & $-19,000$ & $€ 1,140,000$ & $-€ 1,695,000$ & $-€ 247,000$ \\
\hline
\end{tabular}

ED: Emergency departments; LY: Life years; LYG: Life Years Gained; TQS: Tétanos Quick Sticks; TIG: Human tetanus immunoglobulins; N: Cohort size.

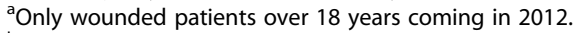

${ }^{b}$ The number of tetanus cases with each strategy was low and comparable; differences in effectiveness was negligible. We therefore only focus on costs and consider that the current analysis is a cost-minimization rather than a cost-effectiveness analysis.

" $\Delta=$ Defined as the delta of the transition from the "Medical Interview" strategy to the "TQS" strategy. 
For patients aged $\geq 65$ years, use of TQS also decreased overall costs, but to a lesser extent $(€ 247,000)$. However, for the non-tetanus-prone wounds cohort, the "TQS" strategy cost more than "Medical Interview" while being more effective. The transition from current practice to the "TQS" strategy however cost $€ 5,292,000 /$ life years gained (LYG). The average cost per patient with "Medical Interview" vs. "TQS" was: $€ 6.2$ " vs. $€ 7.8$ for non-tetanus-prone wounds; $€ 28.9$ vs. $€ 21$ for tetanus-prone wounds; $€ 126.1$ vs. $€ 112$ for patients between $18-64$ years of age and $€ 15$ vs. $€ 14.1$ for patients aged $\geq 65$ years.

\section{Sensitivity analysis \\ One way}

A one-way sensitivity analysis on cost and effectiveness was performed for each variable across their range of plausible values shown in Table 2. Figure 2 shows the parameters values for which the model was most sensitive to the global costs of the strategies' global costs. The proportion of tetanus-prone wounds in the cohort and TQS sensitivity were the parameters whose variation led to the highest change in costs, but without inversion of the preferred strategy. Indeed, a decrease in prophylaxis costs could change the base-case conclusion. For a vaccine cost below $€ 4.9$ (vs. $€ 10$ in the base case), and a TIG cost below $€ 18.5$ (vs. $€ 34.9$ in the base case), "TQS" was no longer cost-saving compared with current practice.

\section{Threshold analysis}

Results of the threshold analysis showed that for a TQS sensitivity under $61.2 \%$ (vs. $69 \%$ in the base case), or a TQS cost over $€ 6.2$ (vs. $€ 4.7$ in the base case), the TQS cost was no longer cost-saving compared with the "Medical Interview" strategy.

\section{Alternative scenarios}

When we considered that patients were treated with equine TIG (which cost $€ 4.1$ vs. $€ 34.9$ for the human TIG in the base case), "TQS" was no longer cost-saving and was associated with an ICER of 875,000 €/LYG. Similar results were observed when we explored the case where a monovalent vaccine was administered $(€ 2.82$ vs. $€ 10$ for the tetravalent vaccine used in the base case) with an ICER of $1,887,000 € /$ LYG (Additional file 1: Technical Appendix). In every other scenarios and sensitivity analysis performed where the "TQS" cost was higher than "Medical Interview", it never appeared to be cost-effective.

\section{Discussion}

We found that in adult patients presenting to the ED with wounds, for comparable effectiveness "TQS" was less expensive than a strategy based on medical interview. The difference in costs was mainly due to the decrease in unnecessary tetanus prophylaxis achieved because of the higher sensitivity of TQS in identifying protected patients who do not need prophylaxis. Subanalyses showed that the "TQS" strategy is especially cost-saving in patients with tetanus-prone wounds, where costly TIG injections are recommended, and for patients with a low tetanus seroprevalence (the elderly). However the TQS cost was higher than current practice for nontetanus prone wounds or when lower prophylaxis costs were explored; and in those cases TQS was associated with high ICER. This was due to the fact the number of cases adverted compared to current practice was always negligible due to low tetanus incidence rates. Therefore, the very small gap in effectiveness between the strategies lead to extremely high ICERs that were never considered cost-effective in the French context $(>3 \times$ French GPD $=$ $€ 90,000$ ).

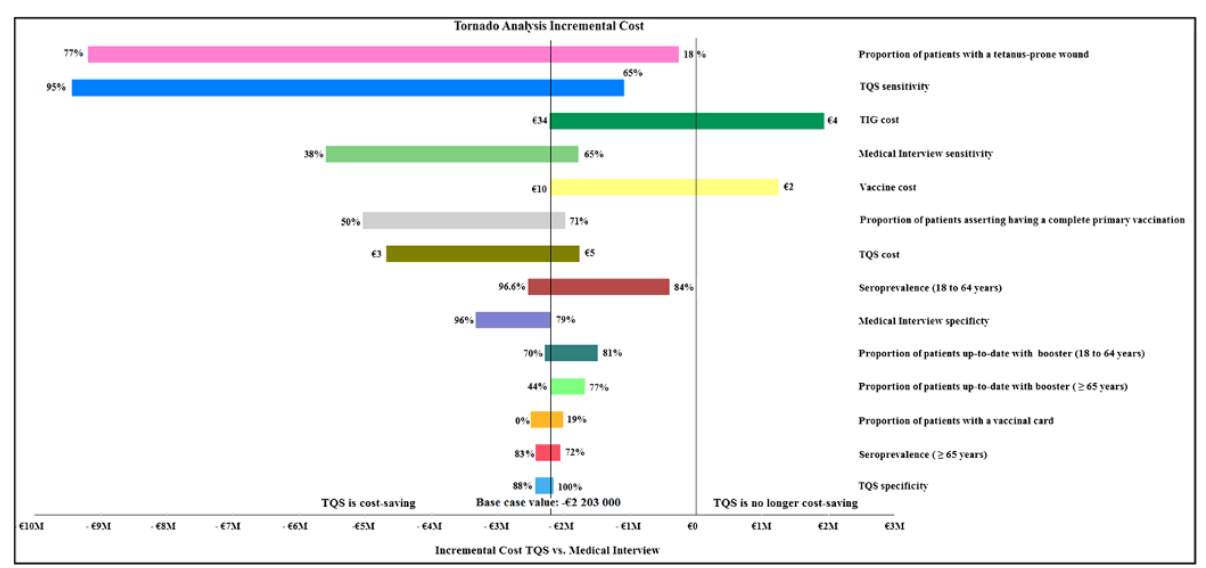

Figure 2 Tornado analysis on strategy incremental costs: incremental cost of the "TQS" strategy compared with the "Medical Interview" strategy (in 2012 Million euros). TQS: Tétanos Quick Stick; TIG: Human tetanus immunoglobulins. 
While few clinical studies have been conducted in other countries, this study is to our knowledge the first model-based study to evaluate the cost-effectiveness of the TQS in France. This study design allows us to simulate the impact of TQS use as well as several alternative scenarios of wound management. Results on effectiveness obtained with our model converge to those reported by French institutions ( $<1$ case of tetanus per year among patients who present to the ED vs. 0.45 in our model for the "Medical Interview" strategy). This illustrates the internal validity of our results.

Our results are consistent with previous epidemiological studies. For example, Hatamabadi et al. found the use of TQS in Tehran, Iran, to be cost-saving for emergency patients with tetanus-prone wounds (average cost per patient $€ 12.1$ with "Medical Interview" vs. $€ 9.5$ with “TQS"), but not for patients with non-tetanus-prone wounds (€0.1 with "Medical Interview" vs. $€ 4$ with the "TQS") [7]. In an assessment of test efficiency in five hospitals in three regions of Belgium (Brussels, Flanders and Wallonia), Stubbe et al. found that TQS use was cost-saving for tetanus-prone wounds for all age groups (€10.6/patient with the "TQS" vs. $€ 11.3$ with "Medical Interview") [14]. However, they found that TQS use did not lead to cost-saving for non-tetanus-prone wounds (€7.3/patient with the "TQS" vs. €3.9/patient with "Medical Interview") [14].

Our results were sensitive to prophylaxis costs. For example, for a TIG cost under $€ 18.5$ or vaccine cost under $€ 4.9$, the "Medical Interview" strategy became less expensive than "TQS". These values are above the cost of equine TIG and of monovalent vaccine, which suggests that TQS use would not be cost-saving if tetanus prophylaxis was solely based on those components. Variation of TQS sensitivity and cost could also change the results. However, their threshold values were outside plausible ranges found in the literature, and very far from values considered in our base case analysis, which were conservative when considering the "Medical Interview" strategy. This illustrates the robustness of our results.

Our study has several limitations. First, our results are valid for the specific French ED setting, wound care management and costs. However, given that wound management is quite comparable, at least in other European countries, our results can probably be extrapolated to other settings. Second, data used for the model came from various studies and some may not represent the French context. However, model inputs were varied over a wide range and our results were robust to these variations. Third, for reasons of feasibility and data availability, only two wound categories were considered. The third category of wounds in French clinical guidelines for tetanus prophylaxis was not considered (Table 1). We included this category (which seems to represent only $4.9 \%$ of all types of wounds observed in EDs [6]) in the "tetanusprone wound" category. Because patients with this third type of wound must receive two TIG injections, this could have resulted in underestimation of the number of TIG injections prescribed in our model. Consequently, this might have led to underestimation of the reduction of prophylaxis costs generated by use of TQS, which further strengthens our results. The same would have been observed if primary vaccination follow-up had been considered; indeed, due to the higher specificity of the TQS, fewer patients incorrectly identified as not having received primary vaccination would have been sent to the general practitioner.

Although the impact of those tests have been evaluated in high income countries, their use could be highly relevant in poorer countries with a higher tetanus incidence due to a lack of tetanus immunity in wounded patients.. In such settings, TQS use could minimize tetanus prophylaxis costs, but more importantly maximize effectiveness in terms of life years gained, due to its high specificity in the detection of unprotected patients.

\section{Conclusions}

In conclusion, in patients seeking care for a wound in French EDs, TQS use is cost-saving compared with the "Medical Interview" strategy. The TQS is especially costsaving in patients with tetanus-prone wounds, and to a lesser extent in patients aged $\geq 65$ years. Therefore, its use should be specifically recommended in this population.

\section{Additional file}

Additional file 1: Technical Appendix. We assessed the effectiveness and cost of TQS use in French emergency departments (EDs) in patients seeking care for a wound, compared with the medical interview regarding vaccination history. We developed a decision-tree model that retraces clinical practice in the ED and includes screening for immunity to tetanus in wounded patients, conditional prophylaxis administration, and risk of tetanus occurrence. Data used as input in the model were found through an extensive literature review. In the Technical Appendix we describe in detail the sources of the probabilities and costs selected as parameters. We explain the methods and provide the formula used to estimate the cohort life expectancy and the patient's tetanus immunity and its identification by the two diagnostic methods compared. We also report in detail how we built incidence rates in non-protected patients who were incorrectly diagnosed, according to their age and type of wound. Finally, we present additional results of the sensitivity analyses conducted as part of this study.

\section{Abbreviations}

c: Cost; ED: Emergency Department; FN: False Negative; FP: False Negative; GP: General practitioner; ICER: Incremental cost effectiveness ratio; LY: Life years; LYG: Life Years Gained; N: Cohort size; NPV: Negative predictive value; Pr: Probability; PPV: Positive predictive value; (TQS): Tétanos Quick Stick ${ }^{\oplus}$; TIG: Tetanus immunoglobulin; TN: True Negative; TP: True Positive; | : Among (in case of a conditional probabilities).

\section{Competing interests}

YY received travel grants, honoraria for presentations at workshops and consultancy honoraria from Abbott, Bristol-Myers Squibb, Gilead, Merck, Roche, Tibotec and ViiV Healthcare. 
JP received travel grants and honoraria for presentations at scientific congresses from Pfizer, Novartis, Gilead and MSD.

The authors declare that they have no competing interest.

\section{Authors' contributions}

YY, MS, and DSN designed the study and the model. DSN collected literature data, which was checked for validity, under the supervision of YY and DO. JP and EC provided advice on the study design to ensure it reflects reality in French emergency rooms. Base case analyses and sensitivity analyses were done by DSN and supervised by YY and MS and DO. DSN drafted the manuscript and al authors contributed substantially to its revision. DSN takes responsibility for the paper as a whole. All authors read and approved the final manuscript.

\section{Acknowledgements}

We thank the language editor David Marsh for his careful revision of the manuscript.

\section{Source of funding}

DSN was funded by a three-year doctoral contract from the graduate school: ED 393 "Public health: epidemiology and biomedical information science". MS, DO and YY were funded by the French National Authority for Health (HAS). JP, SM and EC had no source of funding for this study.

The funders had no role in the study design, data collection and analysis, decision to publish, or preparation of the manuscript.

\section{Presentation information}

This work was presented at the 13th Journées Nationales d'Infectiologie, Tours, France, June 2012; at the 14th Biennial Society for Medical Decision, Oslo, Norway, June 2012; and at the $7^{\text {th }}$ Conférence Francophone d'Épidémiologie Clinique, Paris, France, May 2013.

\section{Author details}

${ }^{1}$ INSERM, IAME, UMR 1137, F-75018 Paris, France. ${ }^{2}$ Université Paris Diderot IAME, UMR 1137, Sorbonne Paris Cité, F-75018 Paris, France. ${ }^{3}$ UPMC Université Paris 06, ED393, F-75005 Paris, France. ${ }^{4}$ Centre Hospitalier et Universitaire de Lille, Service d'Urgence Respiratoire, Réanimation Médicale et Médecine Hyperbare, Université de Lille II, Lille, France. ${ }^{5}$ AP-HP, Hôpital Bichat, Service de Maladies Infectieuses, F-75018 Paris, France. ${ }^{6}$ AP-HP, Hôpital Bichat, Service des Urgences, F-75018 Paris, France.

\section{Received: 27 January 2014 Accepted: 31 October 2014}

\section{0.}

\section{References}

1. The French National Institute for Health Surveillance (InVS) tetanus data from 2000 to 2012 [http://www.invs.sante.fr/Dossiers-thematiques/ Maladies-infectieuses/Maladies-a-prevention-vaccinale/Tetanos/Donneesepidemiologiques]

2. Borrow R, Balmer $\mathrm{P}$, Roper M: The immunological basis for immunisation series. Module 3: Tetanus Update 2006. Geneva: WHO Department of Immunization, Vaccines and Biologicals; 2007. 21 March 2011.

3. The French High Council of Public Health (HCSP) notice on antitetanus vaccination boosters within the context of wound care [http://www.hcsp.fr/ Explore.cgi/Telecharger?NomFichier=hcspa20130524_rappelvaccination antitetanique.pdf]

4. Cavenaile JC, Gérard P, Duchateau J: Évaluation d'un test rapide immunochromatographique comme aide à la prophylaxie antitétanique dans un service d'urgences. Immunoanalyse Biologie Spécialisée 2012, 27(4):185-190.

5. Colombet I, Saguez C, Sanson-Le Pors MJ, Coudert B, Chatellier G, Espinoza $P$ : Diagnosis of tetanus immunization status: multicenter assessment of a rapid biological test. Clin Diagn Lab Immunol 2005, 12(9):1057-1062.

6. Elkharrat D, Sanson-Le-Pors MJ, Arrouy L, Beauchet A, Benhamou F: Evaluation of a bedside immunotest to predict individual anti-tetanus seroprotection: a prospective concordance study of 1018 adults in an emergency department. Emerg Med J 2010, 27(1):36-42.

7. Hatamabadi HR, Abdalvand A, Safari S, Kariman H, Dolatabadi AA, Shahrami A, Alimohammadi $H$, Hosseini M: Tetanus quick stick as an applicable and cost-effective test in assessment of immunity status. Am J Emerg Med 2011, 29(7):717-720.

8. Stubbe M, Swinnen R, Crusiaux A, Mascart F, Lheureux PE: Seroprotection against tetanus in patients attending an emergency department in
Belgium and evaluation of a bedside immunotest. Eur J Emerg Med 2007, 14(1):14-24.

9. Lesimple B, Fievet $P$ : Mise en place du Tétanos quick stick ${ }^{\oplus}$ au service d'accueil des urgences du centre hospitalier de Douai: suivi, évaluation Immunoanalyse Biologie Spécialisée 2005, 20(1):45-48.

10. Gold MR, Siegel JE, Russell LB, Weinstein MC: Cost-effectiveness in health and medicine. New York: Oxford University Press; 1996.

11. Gergely A, Bechet S, Goujon C, Pelicot M, Van Der Vliet D, Simons De Fanti A: La couverture vaccinale contre le tétanos, la poliomyélite et la diphtérie en 2006 dans une population âgée francilienne. Bull Epidémiol Hebd Saint-Maurice: Institut de veille sanitaire 2008, (9):61-64.

12. Directorate for Research, Studies, Evaluation and Statistics (DREES) annual statistical survey on healthcare facilities from 2008 to 2012 [http://www.sae-diffusion.sante.gouv.fr/Collecte_2012/dwd_dwsgen3.aspx]

13. Société Francophone de Médecine d'Urgence : SFMU: Prise en charge des plaies aux urgences In.: http://www.sfmu.org/documents/consensus/ cc_plaies_longue.pdf; Copyright@SFMU 2005

14. Stubbe M, Mortelmans L, Desruelles D, Swinnen R, Vranckx M, Brasseur E, Lheureux PE: Improving tetanus prophylaxis in the emergency department: a prospective, double-blind cost-effectiveness study. Emerg Med J 2007, 24(9):648-653.

15. Elkharrat D, Boyer Chammard A, Raskine L, Durand-Zaleski I, Zerbani A Caulin C, Chastang C: Impact of guidelines to alter antitetanus prophylaxis practices and reduce costs in the emergency department. Am J Ther 1999, 6(4):203-209.

16. Talan DA, Abrahamian FM, Moran GJ, Mower WR, Alagappan K, Tiffany BR, Pollack CV Jr, Steele MT, Dunbar LM, Bajani MD, Weyant RS, Ostroff SM: Tetanus immunity and physician compliance with tetanus prophylaxis practices among emergency department patients presenting with wounds. Ann Emerg Med 2004, 43(3):305-314.

17. Thiebaux A, Claudon C, Demange C: Intérêt clinique et économique d'un test rapide de mise en évidence de l'immunoprotection antitétanique. J de Pharmacie Clinique 2003, 22(1):31-35.

18. The National Institute of Statistics and Economic Studies (INSEE) demographic database [http://www.insee.fr/fr/themes/detail.asp?ref_id=bilandemo\&reg_id=0\&page=donnees-detaillees/bilan-demo/pop_age3.htm]

19. Ardelean-Jaby D, Kaddari-Himeur F, Nkana-Tameze K, Paulin C, Sancho J, Cailliez M: Evaluation of blood test TQS (tetanus quick stick) used in emergency units. Immunoanalyse Biologie spécialisée 2002, 17:330-335.

20. Paulke-Korinek M, Rendi-Wagner P, Kundi M, Tomann B, Wiedermann U, Kollaritsch $\mathrm{H}$ : Pretravel consultation: rapid dipstick test as a decision guidance for the application of tetanus booster vaccinations. J Travel Med 2008, 15(6):437-441

21. The French National Institute for Health Surveillance (InVS) immunization coverage surveys [http://www.invs.sante.fr/Publications-et-outils/Rapports-etsyntheses/Maladies-infectieuses/2012/Mesure-de-la-couverture-vaccinale-enFrance]

22. Guthmann JP, Fonteneau L, Antona A, Lévy-Bruhl D: La couverture vaccinale diphtérie, tétanos, poliomyélite chez l'adulte en France : résultats de l'Enquête santé et protection sociale, 2002. Bull Epidemiol Hebd Saint-Maurice: Institut de veille sanitaire 2007, 51-52:441-445.

23. Antona D: Le tetanos en France entre 2000 et 2001. Bull Epidemiol Hebd Saint-Maurice: Institut de veille sanitaire 2002, 40:197-199.

24. Antona D: Le tétanos en France en 2002-2004. Bull Epidemiol Hebd Saint-Maurice: Institut de veille sanitaire 2006, 7:53-55.

25. Antona D: Le tétanos en France 2005 et 2007. Bull Epidemiol Hebd Saint-Maurice: Institut de veille sanitaire 2008, 30-31:273-275.

26. Antona D: Le tétanos en france en 2008-2011. Bull Epidemiol Hebd Saint-Maurice: Institut de veille sanitaire 2012, (26):53-55.

27. French Online Physicians' Desk Reference database [http://www.vidal.fr/]

28. The Agency for Information on Hospital Care (ATIH) 2010 costs database [http://www.atih.sante.fr/index.php?id=0009200003FF]

\section{doi:10.1186/s12879-014-0603-3}

Cite this article as: N'Diaye et al:: Effectiveness and cost of quick diagnostic tests to determine tetanus immunity in patients with a wound in french emergency departments. BMC Infectious Diseases 2014 14:603. 